\title{
Preventing Accidents from Reoccurring due to Colour Coding Transition in Malaysian Market: a Stakeholder Analysis
}

\author{
Amar Hisham Jaaffar ${ }^{1 *}$, Jegatheesan Rajadurai ${ }^{2}$, Shahrul Suhaimi Ab. Shokor ${ }^{3}$, Zurina Ismail ${ }^{4}$, Mohd Nur \\ Ruzainy Alwi ${ }^{5}$ \\ ${ }^{1,3,4}$ Institute of Energy Policy and Research (IEPRe), Universiti Tenaga Nasional (UNITEN), Malaysia \\ ${ }^{2,5}$ College of Business Management and Accounting (COBA), Universiti Tenaga Nasional (UNITEN), Malaysia \\ *Corresponding author E-mail: Ahisham@ uniten.edu.my
}

\begin{abstract}
The harmonization of cable colour code for electrical installation with the current international standard is very important for Malaysia to ensure supply cables, reliable quality, and reasonable cable price in the Malaysian market as well increase its cable's export to all countries around the world. As the new cable colour code will associate with the change of the colour of the cored cable (e.g. black cored cable former neutral and later phase and blue cored cable former phase and later neutral), the adjustment may increase risk of electrical accidents due to confusion in cable colour code in wiring process. Therefore, a proper action and implementation plan is crucial in handling the cable colour changeover in the hope to safeguarding the safety of electrical trade workers as well as the general public in Malaysia. By using stakeholder analysis, this study propose the action and implementation plan which aimed zero electrical accidents during the cable colour code changeover in Malaysian market.
\end{abstract}

Keywords: Electrical Installation; Electrical Accident; Stakeholder Analysis; Malaysia

\section{Introduction}

Electrical installation is schemed based on a specific standard including colour code of the cable. It us routinely used a copper wires which comprise three conduit where their function including live, earthed or neutral. The cable colour code in Malaysia currently follow the British Standard where the live wire is coded as red, blue or yellow; neural wire is coded as black; and green/yellow wire is coded as earthed. Each wire is covered in a first layer of plastic wire insulation. While the three different function wires are packeted in thermoplastic jacket that is both hear and current resistant. The domestic electrical installation in Malaysia usually features with single and the phase systems where the commercial building usually came out with three phase systems (supply with nominal voltage of $400 \mathrm{~V}$, range $+10 \%,-6 \%$, with the permitted frequency is $50 \mathrm{~Hz}+1 \%$ ).

In Malaysia, electrical wiring in residential building is under the authority of Energy Commission. In 2008, the Energy Commission produced and released "The Guidelines for Electrical Wiring in Residential Buildings", in an effort to ensure that electrical wiring works were carried out in accordance with established safety procedures and regulations. This Guideline is based on the "Electricity Supply Act of 1990 and others regulation and worlwide standard bodies such as Department of Standard Malaysia, Malaysia Energy Commission and International Electrotechnical Commission (IEC) (Energy Commission Malaysia, 2014). One of the important elements in the guidelines of electrical installation is cable colour code. The current cable colour code for fixed cable (e.g., in-, on-, or behind-the-wall cables) in Malaysia is Blue, Yellow, and Red for phases conductor, Black for neutral conductor, and Green-Yellow for protective earth/ground conductor (Based on MS IEC 60364:2003 Standard). In Malaysia, for the flexible cable used for extension, power, and lamp cords, the cable colour colour code is Grey, Black, and Brown for phase's conductor, Blue for neutral conductor, and Green-Yellow for protective earth/ground conductor. Recently there is a called for Malaysia domestic market to change the cable colour code in accordance to IEC 60445 for fixed electrical installation. Therefore, a proper action and implementation plan is crucial in handling the cable colour changeover in the hope to safeguarding the safety of electrical related workers, trade, and the public in Malaysia particularly when the changes become mandatory.

IEC 60445:2010 is "a current standard applies to the identification and marking of terminals of electrical equipment such as resistors, fuses, relays, contactors, transformers, rotating machines and, wherever applicable, to combinations of such equipment (e.g. assemblies), and also applies to the identification of terminations of certain designated conductors". "It also provides general rules for the use of certain colours or alphanumeric notations to identify conductors with the aim of avoiding ambiguity and ensuring safe operation". (Šućur \& Ćućilo, 2017). These conductor colours or alphanumeric notations are designed to be employed in cables or cores, busbars, electrical equipment and installations. The new colour coding according to the standard of IEC 60445 have changed to grey, black, and brown (for live); blue (for neutral); and green/yellow (for earth) (As shown in Figure 1). 


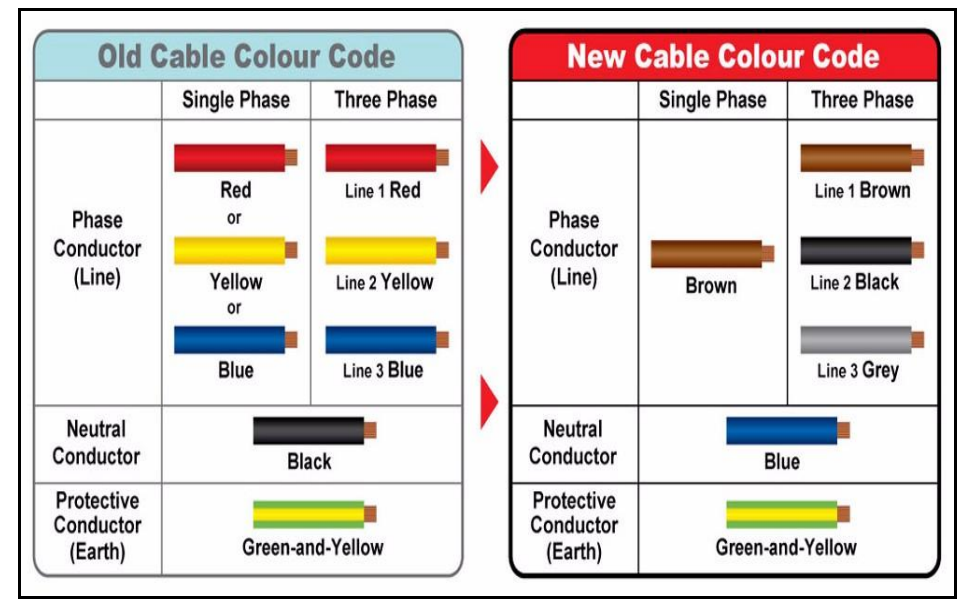

Fig. 1: The New Cable Colour Code based on IEC 60445 Standard.

Since many major countries such as United Kingdom, major European Countries, China, Japan, Russia, South Africa, Ukraine, Belarus, Kazakhstan, Hong Kong, Singapore, Argentina, and Indonesia have acquired the new cable colour code, the reserve and production of cable in the old colour code will unavoidably be affected particularly imported cable countries. The cable manufacturers and the exported cable countries will switch to manufacturing cables in the new colour code and, therefore, no longer keep the old colour coded cables in stock because of lack of demand by the market. The market for cable with new coloud codes will significantly expanded and the manufacterers or the exported cable countries are probably to choose producing new colour coded cables only. For that reason, the ignorance to new cable colour code, will increase the cost of prohects in Malaysia as contractors will need to place special orders for certain types of old colour coded cables in the future. This will affect the cost and timing of projects associated with Malaysian market (Leung \& Ho, 2009).

Furthermore, the changes to the colour code will not only affect cable manufacturers and electrical contractors but various stakeholders such as Suruhanjaya Tenaga (as the Malaysian Energy Regulator), the Department of Standard Malaysia, consumers and education providers. It will also affect professional electricians, wiremen and institutions adopting the new system, increase the probability of electrical accidents during the transition to the new system, raise concerns about existing buildings with the old colour code system, raise concerns for consumers who 'do-ityourself" wiring in their homes, be a concern for consumers who are unfamiliar with the colour code system, and mean changes to the syllabus in the Malaysian education system related to electrical wiring. Therefore, it is important to identify and analyse the antecedents that could lead to electrical accidents during the transition.

\section{Literature Review}

\subsection{Stakeholder Perspective}

Stakeholder analysis is "an effective technique to evaluate the stakes of different involved parties in a detail method" (Grimble, Aglionby, \& Quan, 1994). According to Grimble and Wellard (1997), stakeholder analysis can be viewed as "a comprehensive method to comprehend the system and changes in by recognizing the stakeholders and evaluating their respective interests in the institutional setting". In term of safety research, stakeholder analysis become important mechanism to minimize the gaps among stakeholders related to safety issues (Hernandez \& Saquido, 2018). This analysis also important because it allows the systematic evaluation and similarity of stakeholder specifically "sets of interests, influences and roles, and the examination of relationships between them" (Raum, 2018). In this study stakeholders can be regarded as a persons, groups or institutions who have an interest and impact in the changes to the new colour coding under consideration. The inputs of stakeholder analysis is very important to identify the risk and safety impact involved with the embracement of a new colour code. The risks associated with the changes then will be carefully evaluated by an expert who considered installation guidelines to prevent technical faults and minimised the risks of electrical accidents.

\subsection{Risks of Electrical Work}

Electrical works involves lots of risky operation, work that engaged with electricity faced prominent risk of electrocution as a primary electrical accident (Wong, Chan, Wong, Hon, \& Choi, 2018). Workers that engage in electricity activity are exposed tpo electric shock risk such as electricity shock, flash over and fire, while operating on the conductive segments of the electrical cable. The changes of the new colour code will lead to confusion on the installation of the cable (e.g. the colour code of the cable) (which consequently lead to connection faulty. The risks associated of the incorrect installation may lead to possible short-circuits and electrical casualty.

\section{Methodology}

To perform stakeholder analysis, several data collection methods were employed including literature and desk research; Focus Group Study; Dialog with representative of stakeholders group; and Stakeholder Impact Survey. Literature and desk research are based on secondary data such as standards of electrical installation, circulars, policies, guidelines, scientific and engineering articles, reports, books, and past studies, along with other sources (e.g. official web sites, news reports, and on-line announcements). Focus group research is "a method of obtainig qualitative data, which primarily involves engaging a small number of people in an informal group discussion, concentrated around a particular topic or set of issues" (Wilkinson, 2004, p. 177). Industrial Dialogues are important platforms for this study to enable a participatory moment where different actors or stakeholders share their views and collaborate in an active way in the issues related to changes to the cable colour code. Stakeholder impact survey was carried out to analyse the impact on stakeholders of the changes to the cable colour code, it is indispensable to recognize and incorporate the factors which create the impact (Nguyen et al., 2009). Stakeholder classification method is a widely used technique by previous studies where according to Mitchell et al. (1997), stakeholders are classified by "various combinations of attributes including power, legitimacy and urgency". The levels of these attributes basically impel the degree of stakeholder importance in relation to cable 
colour code changes. Stakeholder impact analysis is computed by the following formula:

$I=P+L+U+K+D$

Where $I=$ stakeholder impact level; $P=$ stakeholder power level; $U=$ stakeholder urgency level; $L=$ stakeholder legitimacy level; $K=$ stakeholder knowledge level; and $D=$ stakeholder proximity degree.

\section{Results and Discussion}

\subsection{Analysis}

The purpose of stakeholder analysis is to identified stakeholder requirement. In this research, the stakeholders which involved Power Company; Electrical Contractor, Consultant and Professional Institution; Academic Institutions; Public bodies and government department; and Electrical Trade Union and Consumer. Figure 2 shows the stakeholder matrix analysis derived from literature and desk research. Among the safety risk issues addressed by the stakeholders in facing the cable colour changes obtained from Focus Group Study and Dialog with representative of stakeholders group were: 1) Based on the new colour code, the colour of the live and neutral wire will be effected and will lead to mistake in installation; 2) A very detail technical guideline must be provided in single phase and the third phase installation. To ensure electrical safety, it is recommended not to carry out, whenever practicable, works on "LIVE" installations at any cable colour change interfaces; 3) How to handle extension of mix cable colour code; and 4) Benefits of the cable colour coded changes.

Table 1 demonstrates the outcomes of stakeholder impact analysis obtained through the questionnaire to 70 stakeholders. Based on the analysis, it has been found that Public bodies and government department have the highest impact on the changes to new cable colour code; follow by power company and academic institution. Electrical trade union and consumer have the lowest impact. Based on the results obtained from literature and desk research; focus group study; dialog with representative of stakeholders group; and stakeholder impact survey, the risk and safety impact due to the changes to new colour code have been conducted by the electrical expert. This risk and safety impact analysis was carried out using Zachman framework which based on six basics questions (what, how, when, who, where, and why) (Iyamu, 2018). The action plan to mitigate electrical safety risks is shown in Figure 2. Based on the result on Figure 2, the safety risk mitigation plan is develop based on three important activities including: 1) Guidelines / Regulations / Code of Practice Formulation; 2) Provision of a Training Session ; and 3) Provide publicity for stakeholders and the public (including electrical workers) (Leung \& Ho, 2009)

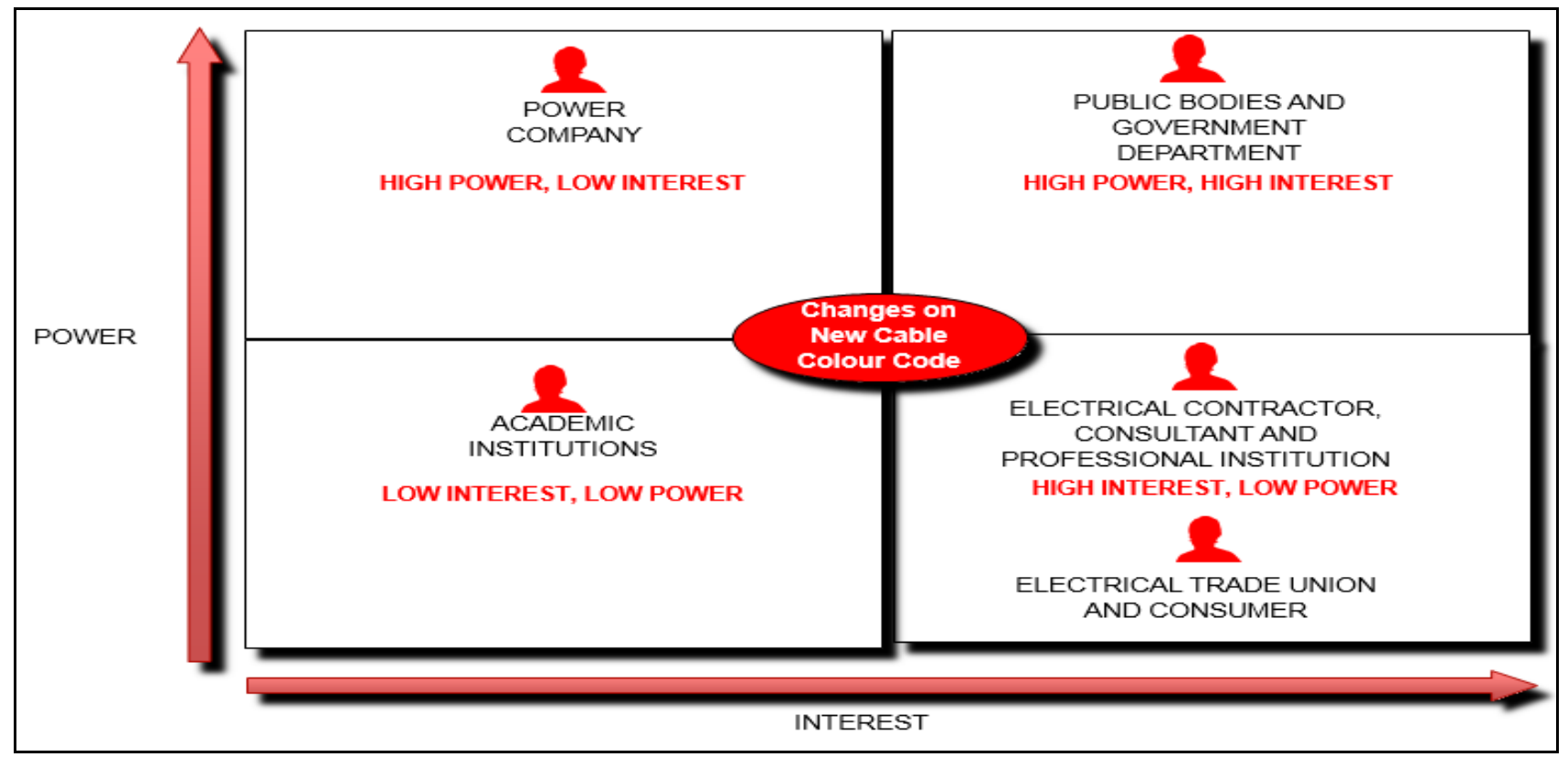

Fig. 2: Stakeholder Matrix Analysis

Table 1: Outcomes of Stakeholder Impact Analysis

\begin{tabular}{|l|l|l|l|l|l|l|}
\hline $\begin{array}{l}\text { Stakeholder's } \\
\text { Type }\end{array}$ & Power & Legitimacy & Urgency & Proximity & Knowledge & $\begin{array}{l}\text { Stakeholder } \\
\text { Impact }\end{array}$ \\
\hline Power Company & $\begin{array}{l}\text { Medium Level of } \\
\text { Power }\end{array}$ & $\begin{array}{l}\text { Contractual } \\
\text { Relationship }\end{array}$ & Immediate Action & Fully Involve & Not Aware & 13 \\
\hline $\begin{array}{l}\text { Electrical } \\
\text { Contractor, } \\
\begin{array}{l}\text { Consultant and } \\
\text { Professional } \\
\text { Institution }\end{array}\end{array}$ & $\begin{array}{l}\text { Medium Level of } \\
\text { Power }\end{array}$ & $\begin{array}{l}\text { Moderate } \\
\text { Contractual } \\
\text { Relationship }\end{array}$ & Immediate Action & Involve & $\begin{array}{l}\text { Aware by just } \\
\text { small amount }\end{array}$ & 12.5 \\
\hline $\begin{array}{l}\text { Academic } \\
\text { Institution }\end{array}$ & $\begin{array}{l}\text { Medium Level of } \\
\text { Power }\end{array}$ & $\begin{array}{l}\text { Moderate } \\
\text { Contractual } \\
\text { Relationship }\end{array}$ & Immediate Action & Fully Involve & $\begin{array}{l}\text { Aware by just } \\
\text { small amount }\end{array}$ & 12.6 \\
\hline $\begin{array}{l}\text { Public bodies and } \\
\text { government } \\
\text { department }\end{array}$ & $\begin{array}{l}\text { Higher Level of } \\
\text { Power }\end{array}$ & $\begin{array}{l}\text { Contractual } \\
\text { Relationship }\end{array}$ & Gradual Action & Fully Involve & Aware & 13.6 \\
\hline $\begin{array}{l}\text { Union and } \\
\text { Consumer }\end{array}$ & $\begin{array}{l}\text { Medium Level of } \\
\text { Power }\end{array}$ & $\begin{array}{l}\text { Moderate } \\
\text { Contractual } \\
\text { Relationship }\end{array}$ & Immediate Action & Involve & $\begin{array}{l}\text { Aware by just } \\
\text { small amount }\end{array}$ & 10 \\
\hline
\end{tabular}




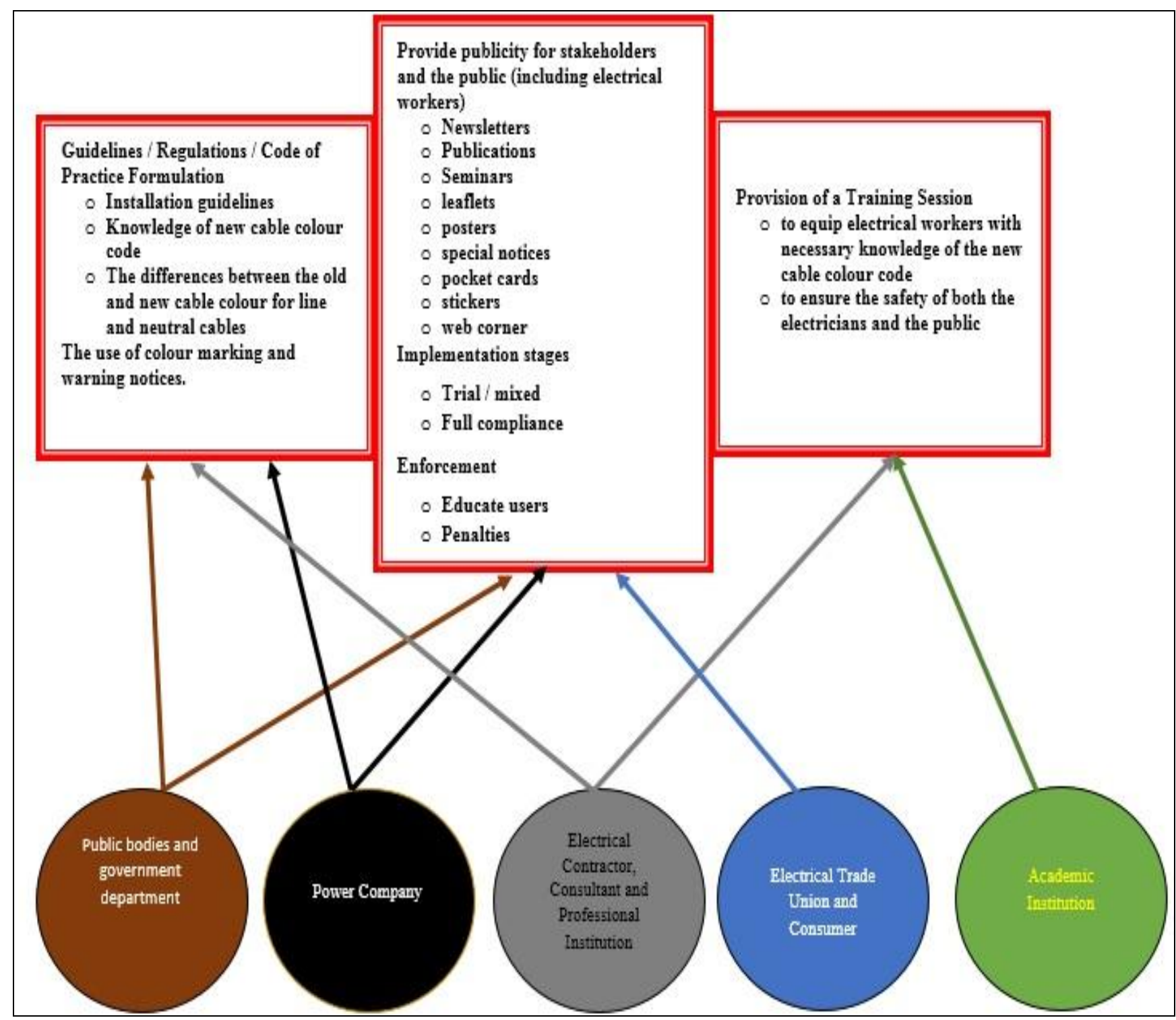

Figure 2: Safety Risk Mitigation Plan

\section{Conclusion}

Managing a cable colour code change that will affect the whole spectrum of trade and the public at large will be a challenging task. The cable colour change will affect the safety of electrical workers and the public, for which no compromise can be tolerated. A safe and smooth implementation relies on a shared vision, collaboration, participation and support of all stakeholders. Stakeholder analysis is become important techniques to minimize the risk associated with the change so as to ensure that the change is implemented safely and smoothly. Moreover, without a sound stakeholder analysis, it is very difficult to reach mutual consensus among all stakeholders to prevent accidents from reoccurring if the changes of new cable colour code occurred in Malaysia market.

\section{Acknowledgement}

Special thanks to Suruhanjaya Tenaga Malaysia for funding this research under the Chair of Energy Economics Programme.

\section{References}

[1] Asrokin, M. K. A. Rahim, A. N. Z. Abidin, N. Hashim, and S. Ab Azis, "Cable modeling comparison for twisted-pair copper plant in malaysia," in Control System, Computing and Engineering (ICCSCE), 2015 IEEE International Conference on, 2015, pp. 359364. http:// 10.1109/ICCSCE.2015.7482212

[2] Electrical and Mechanical Services Department [EMSD] (1997), Code of Practice for the Electricity (Wiring) Regulations, Hong Kong.

[3] Energy Commission Malaysia (2008). "Guidelines for Electrical Wiring in Residential Buildings." Suruhanjaya Tenaga, Putrajaya (2008): 6.

[4] Energy Commission Malaysia. (2014). Energy Malaysia. Prioritising the public. Protecting the interest of energy consumers. Volume 4. Putrajaya, Malaysia.

[5] Grimble, R., Aglionby, J., \& Quan, J. (1994). Tree resources and environmental policy: a stakeholder approach (Vol. 7): Natural Resources Institute.

[6] Grimble, R., \& Wellard, K. (1997). Stakeholder methodologies in natural resource management: a review of principles, contexts, experiences and opportunities. Agricultural systems, 55(2), 173-193.

[7] Hernandez, P. M. R., \& Saquido, A. S. B. (2018). Analysis of Gaps Among Stakeholders of occupational Health and Safety in the Philippines. ACTA MEDICA PHILIPPINA, 52(3), 282. 
[8] Iyamu, T. (2018). Implementation of the enterprise architecture through the Zachman Framework. Journal of Systems and Information Technology, 20(1), 2-18.

[9] Leung, K., \& Ho, W. (2009). Managing the change of cable colour code in Hong Kong

[10] Nguyen, N. H., Skitmore, M., \& Wong, J. K. W. (2009). Stakeholder impact analysis of infrastructure project management in developing countries: a study of perception of project managers in state-owned engineering firms in Vietnam. Construction Management and Economics, 27(11), 1129-1140.

[11] Mitchell, R. K., Agle, B. R., \& Wood, D. J. (1997). Toward a theory of stakeholder identification and salience: Defining the principle of who and what really counts. Academy of management review, 22(4), 853-886.

[12] Raum, S. (2018). A framework for integrating systematic stakeholder analysis in ecosystem services research: Stakeholder mapping for forest ecosystem services in the UK. Ecosystem Services, 29, 170-184

[13] Šućur, M., \& Ćućilo, D. (2017). Standardization in Bosnia and Herzegovina-Today's Approaches and Future Challenges. In Advanced Technologies, Systems, and Applications (pp. 103-114): Springer.

[14] Wilkinson, S., \& Silverman, D. (2004). 10 Focus Group Research. Qualitative research: Theory, method and practice, 177-199.

[15] Whitfield, J. F. (2012). The Electrician's Guide to the 17th Edition of the IEE Wiring Regulations BS 7671: 2011 and Part P of the Building Regulations: EPA Press.

[16] Wong, F. K., Chan, A. P., Wong, A. K., Hon, C. K., \& Choi, T. N (2018). Accidents of electrical and mechanical works for public sector projects in Hong Kong. International journal of environmental research and public health, 15(3), 485. 